\title{
Deficient control of in vitro Epstein-Barr virus infection in patients with ankylosing spondylitis
}

\author{
STUART ROBINSON AND GABRIEL S PANAYI \\ From the Rheumatology Unit, Division of Medicine, United Medical and Dental Schools, Guy's Hospital, \\ London
}

SUMmaRY Infectious Epstein-Barr (EB) virus obtained from the B95-8 marmoset cell line was used to infect mononuclear cells from healthy controls and patients with rheumatoid arthritis (RA) and ankylosing spondylitis (AS), and outgrowth of B cells into lymphoblastoid cell lines was assessed by visual microscopy and uptake of tritiated thymidine over a 28 day period. When undiluted virus was used lymphocytes from both patients with AS and RA and from normal controls outgrew into lymphoblastoid cell lines (LCLs) by day 28 of culture. At dilutions of 1/10, $1 / 20$, and $1 / 40$, however, the control cells showed regression of proliferation at approximately day 14 of culture, whereas the cells from patients with AS and RA continued to proliferate and outgrew into LCLs (transformation scores of cells from patients with AS compared with controls at day $28 \mathrm{p}<0.05$ in all cases; thymidine uptake at a 1/40 dilution at day 28 , patients with AS compared with controls $\mathrm{p}<0 \cdot 01$ ). Hence these results suggest that there is a defect in the cellular response to $\mathrm{EB}$ virus induced $\mathrm{B}$ cell proliferation in patients with AS similar to that seen with cells from RA donors.

Key words: rheumatoid arthritis, B lymphocytes, lymphoblastoid cell lines, immune regulation.

Epstein-Barr (EB) virus is a herpes virus that selectively infects $B$ lymphocytes, inducing proliferation and lymphoblastoid cell line (LCL) formation in in vitro culture. With cells from normal immune donors outgrowth is controlled by $\mathrm{T}$ cell mechanisms that inhibit the proliferative response at about day 12 of culture. ${ }^{1}$ With cells from patients with rheumatoid arthritis (RA), however, no such regression is seen, and cultures outgrow into LCLs at high frequency. ${ }^{2}$ A similar phenomenon has been reported with cultured cells from patients with multiple scilerosis (MS) ${ }^{3}$ It is of interest to determine, therefore, whether this type of defect is disease specific or is a result of chronic inflammation. With this in mind we have investigated the behaviour of cells from patients with ankylosing spondylitis (AS) in this type of in vitro system at different doses of infectious virus, since an effective $T$ cell response to in vitro $E B$ virus infection should be able to prevent $B$ cell outgrowth at a higher infecting dose of virus than that seen with deficient

Accepted for publication 21 May 1986

Correspondence to Professor G S Panayi, Rheumatology Unit, Division of Medicine, Guy's Hospital, London SE1 9RT.
$T$ cell response. In the event we show that $B$ lymphocytes from patients with AS explant more frequently after EB virus infection in a manner comparable to the deficit seen in RA. These findings indicate that this defect is not disease specific.

\section{Patients and methods}

PATIENTS

Heparinised blood samples were collected from patients with AS and RA attending the rheumatology outpatients clinic at Guy's Hospital. Normal controls were healthy laboratory volunteers. All subjects studied had demonstrable antibodies to viral capsid antigen in their serum as measured by indirect immunofluorescence.

SEPARATION OF MONONUCLEAR CELLS Heparinised blood samples (10 U heparin/ml) were diluted with an equal volume of Hanks's balanced salt solution (HBSS) pH 7.2 (Gibco). Diluted blood $(20 \mathrm{ml})$ was layered onto $6 \mathrm{ml}$ of Lymphoprap (Nyegaard) and centrifuged at $400 \mathrm{~g}$ for 20 minutes at $20^{\circ} \mathrm{C}$. The mononuclear cells were removed from the interface with a Pasteur pipette and resuspended 
in HBSS. Contaminating platelets were removed by centrifugation at $300 \mathrm{~g}$ for 10 minutes at $4^{\circ} \mathrm{C}$, whereupon the cell pellet was washed a further three times in HBSS to remove serum contaminants before use.

PREPARATION OF INFECTIOUS EB VIRUS Infectious virus was obtained from the supernatant of cultures of the B95-8 marmoset lymphoblastoid cell line. B95-8 cells were cultured in RPMI 1640 medium (Gibco) supplemented with $10 \%$ fetal calf serum (Sera Lab), 0.4 mM L-glutamine, and $10^{4} \mathrm{U}$ penicillin-streptomycin (Gibco) (supplemented RPMI 1640). Supernatant from seven day cultures was filtered through a $0.25 \mu \mathrm{m}$ filter (Millipore) before being stored in aliquots at $-70^{\circ} \mathrm{C}$.

INFECTION OF B CELLS BYEB VIRUS AND

THEIR SUBSEQUENT CULTURE

The mononuclear cells were pelleted by centrifugation at $150 \mathrm{~g}$ for 10 minutes at $4^{\circ} \mathrm{C}$. One millilitre of viral supernatant (B95-8), diluted in supplemented RPMI 1640 , was added per $10^{7}$ mononuclear cells and the suspension incubated for one hour at $37^{\circ} \mathrm{C}$. The blood cells were then resuspended in supplemented RPMI 1640 at $10^{6}$ cells/ml and cultured in $1 \mathrm{ml}$ volumes in Linbro 24 well, flat bottomed, tissue culture plates (Flow) at $37^{\circ} \mathrm{C}$. Cells were fed at seven day intervals with fresh supplemented RPMI 1640, being cultured for 28 days.

ASSESSMENT OF CELLULAR PROLIFERATION Visual assessment

Cellular proliferation was assessed by light microscopy at seven day intervals using a numbering system. ${ }^{4}$ A score of 1 indicated dead cells, 2-living but not necessarily transformed cells, 3 -clumps of proliferating cells, and 4-a culture over-run with proliferating and transformed cells.

\section{Tritiated thymidine uptake}

In addition to the visual assessment method, each well was pulsed with $0.2 \mu \mathrm{Ci}$ tritiated thymidine $\left({ }^{3} \mathrm{H}-\mathrm{TdR}, 1 \mathrm{mCi} / \mathrm{ml}\right.$; Amersham) at day 28 of culture. After incubation for a further 24 hours at $37^{\circ} \mathrm{C}$ the well contents were harvested onto cellulose discs and thymidine uptake measured by scintillation counting.

All cultures, both for visual assessment and for measurement of the incorporated tritiated thymidine, were performed in triplicate.

Statistical analysis was performed by the MannWhitney U test.

\section{Results}

VISUAL ASSESSMENT OF OUTGROWTH

Fig. 1 shows the transformation responses of cells

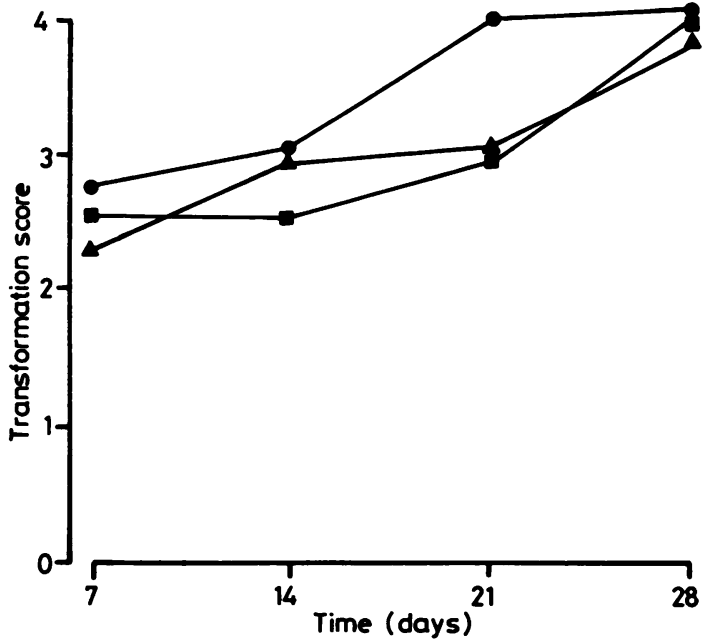

Fig. 1 Transformation responses of mononuclear cells from patients with $A S(n=6)$, patients with $R A(n=3)$, and normal $(n=5)$ donors when infected with neat $B 95-8$ supernatant. $=A S, \square=R A$, $\Delta-\mathbf{\Delta}=$ normals.

from normals and from patients with RA and AS when infected with undiluted B95-8 supernatant and cultured for 28 days. All three groups responded to the virus and outgrew into LCLs by day 28 of culture. No $\mathrm{T}$ cell mediated regression was seen in the cultures of cells from normal controls. Therefore it was not possible to determine whether the outgrowth of the cells from AS donors was a result of defective $T$ cell immune mechanisms.

Figs $2 \mathrm{a}, \mathrm{b}, \mathrm{c}$, and $\mathrm{d}$ show the proliferative responses of the same donors over the 28 day culture period when the cells were infected with dilutions of B95-8 supernatant of $1 / 10,1 / 20,1 / 40$, and $1 / 80$, respectively. From a viral dilution of $1 / 10$ to $1 / 80$ outgrowth of cells from AS and RA donors into LCLs was seen, whereas normal controls showed some proliferative response and then regressed by day 28 . At dilutions of $1 / 10,1 / 20$, and $1 / 40$ the transformation scores of cells from patients with AS compared with normals at day 28 were significantly different ( $p<0.05$ in all cases). We have, therefore, shown that cells from patients with AS are less able to cope with in vitro virus induced proliferation than those from normal controls and respond in a similar manner to cells from patients with RA. Fig. 3 shows the responses of cells cultured without virus, demonstrating that the proliferative effects seen in this series of experiments were a result of viral superinfection and not due to spontaneous explantation. 


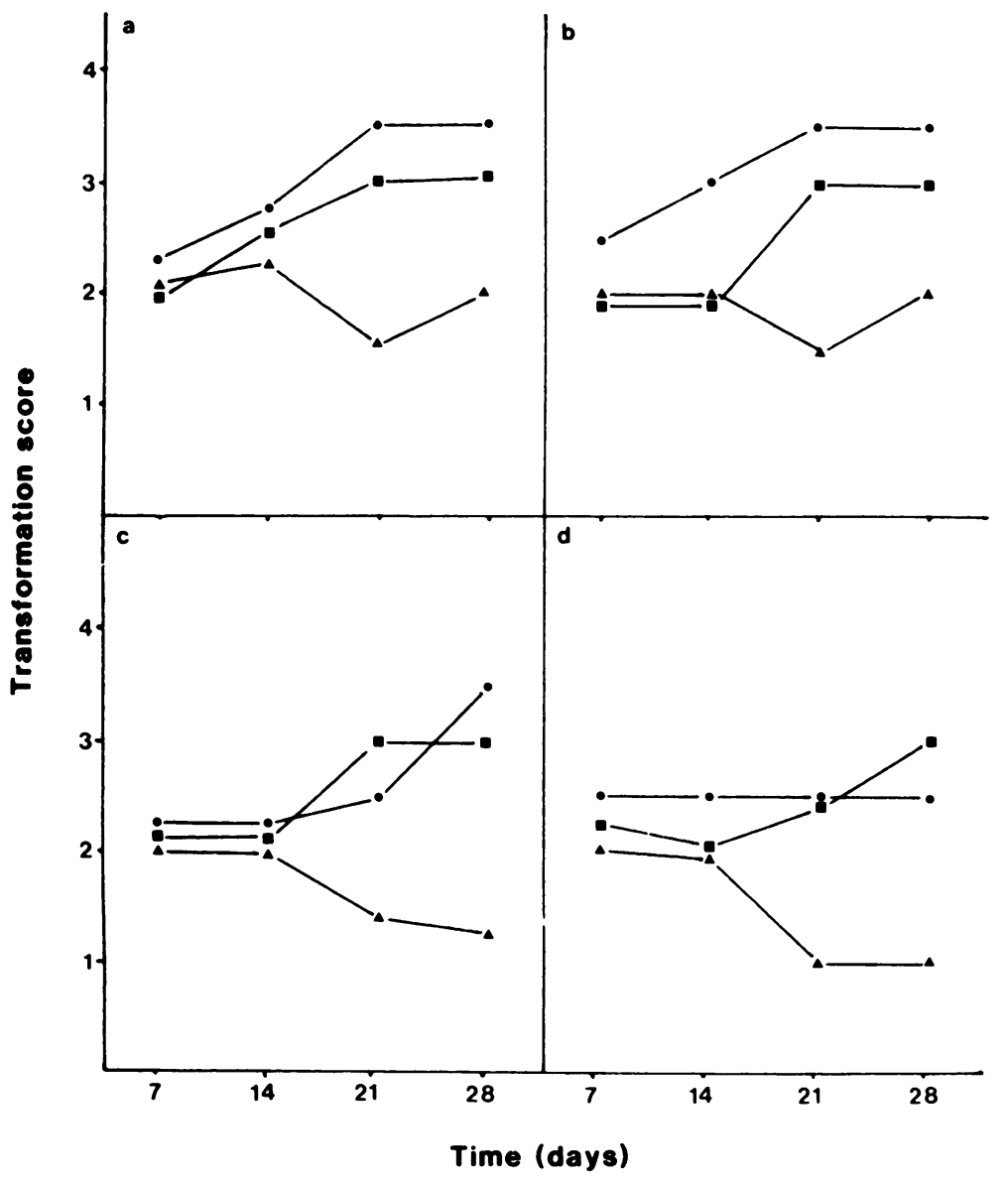

Fig. 2 Transformation responses of mononuclear cells from patients with $A S$, patients with $R A$, and normal donors when infected with B95-8 supernatant at dilutions of (a) $1 / 10$, (b) $1 / 20$. (c) $1 / 40$, and (d) 1/80. Numbers of donors and symbols as for Fig. 1.

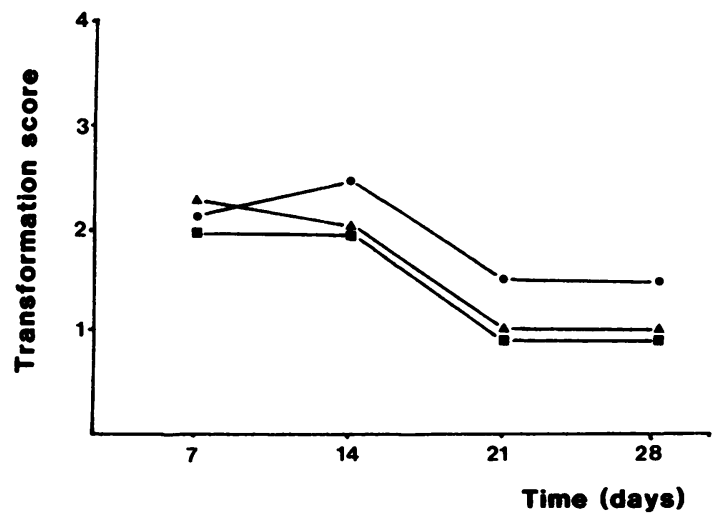

Fig. 3 Transformation responses of mononuclear cells from patients with $A S$, patients with $R A$, and normal donors without viral infection. Numbers of donors and symbols as for Fig. 1.
THYMIDINE UPTAKE EXPERIMENTS

The uptake of tritiated thymidine between day 28 and 29 of culture at the various viral dilutions by cells from patients with AS and from normal controls are shown in Fig. 4. At viral dilutions of 1/1, $1 / 10$, and $1 / 20$ cells from normal individuals showed a high uptake of isotope, indicating the presence of actively proliferating cells. At dilutions of virus of $1 / 40$ and 1/80 no such uptake was seen-the cell cultures had regressed and no cellular activity was noted. With the cultures of cells from the patients with AS a similar situation was seen at viral dilutions of $1 / 1,1 / 10$, and $1 / 20$ as with normal controls, with outgrowth into LCLs taking place. At a viral dilution of $1 / 40$, however, cells from patients with AS continued to proliferate, whereas normal cells had regressed. This difference is statistically significant $(p<0 \cdot 01)$, confirming that our $B 95-8$ supernatant at a dilution of $1 / 40$ was able to induce $L C L$ 


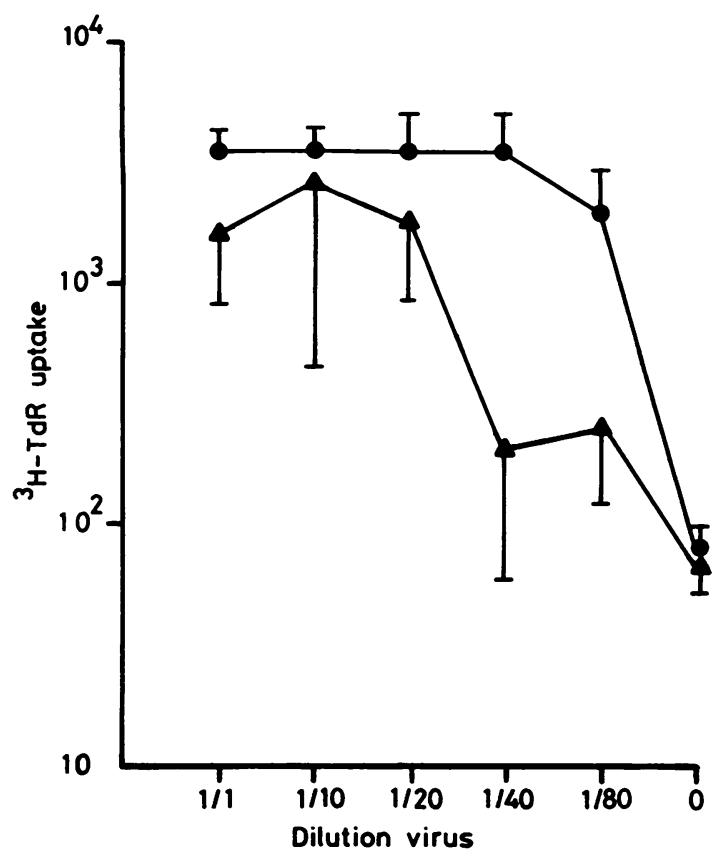

Fig. 4 The proliferative response of cells from patients with AS (-) and from normal controls ( $\mathbf{\Delta}-\mathbf{\Delta})$ to varying dilutions of B95-8 supernatant as measured by tritiated thymidine uptake at day 28 of culture. The vertical lines represent standard error of the mean.

formation with cells from patients with AS but not with those from normal controls.

\section{Discussion}

The results presented in this paper suggest that there is a defect in the ability of mononuclear cells isolated from patients with AS to control EB virus induced $B$ cell proliferation in in vitro culture. This is an effect similar to that reported in cell cultures derived from the blood of patients with RA. In the case of RA the defect has been traced using cell depletion experiments to a deficiency in the cytotoxic $T$ cell response. ${ }^{5}$ Whereas we have not confirmed that the mechanism is the same in the case of AS, it would not be unreasonable to assume that this is likely.
There has also been a report that the defect seen in $\mathrm{RA}$ is linked to a deficiency in gamma interferon production by those cells. ${ }^{6}$

It is apparent that even when cells from donors with a competent response to EB virus are used the responses can be overwhelmed by high concentrations of infectious virus. It is likely that the use of such quantities of virus results in a greater proportion of the susceptible B cells becoming infected, and, since in in vitro culture no recruitment of competent $T$ cells is possible from the circulation, the resultant $\mathrm{B}$ cell proliferation is too great for the available $T$ cells, and LCLs result.

The relevance of this finding to current ideas about the aetiopathogenesis of AS is not clear. It would be unreasonable to assume (as has been done to some extent with RA) that such an effect implicates EB virus as a possible initiating agent of AS. The conditions of AS, RA, and MS are too varied to implicate a similar disease mechanism, more probable is the possibility that in vitro EB virus infection is a useful model for examining immune status during the course of chronic inflammatory disease.

This work was supported by a programme grant from the Arthritis and Rheumatism Council.

\section{References}

1 Moss D J, Rickinson A B, Pope J H. Long term T-cellmediated immunity to Epstein-Barr virus in man. I. Complete regression of virus-induced transformation in cultures of seropositive donor leukocytes. Int J Cancer 1978; 22: 662-8.

2 Slaughter L, Carson D A, Jensen F C, Holbrook T L, Vaughan $\mathrm{J} \mathrm{H}$. In vitro effects of Epstein-Barr virus on peripheral blood mononuclear cells from patients with rheumatoid arthritis and normal controls. J Exp Med 1978; 148: 1429-34.

3 Craig, J C, Haire M, Millar J H D, Fraser K B, Merrett J D. Immunological control of Epstein-Barr virus transformed lymphocytes in multiple sclerosis. Clin Immunopathol 1983; 29: 86-93.

4 Thorley-Lawson D A, Chess L, Strominger J L. Suppression of in vitro EBV infection-a new role for adult $T$ lymphocytes. $J$ Exp Med 1977; 146: 495-508.

5 Tosato G F, Steinberg A D, Blaese M. Defective EBV-specific suppressor $\mathrm{T}$ cell function in rheumatoid arthritis. $N$ Engl $J$ Med 1981; 305: 1238-43.

6 Hasler F, Bluestein H G, Zvaifler N J, Epstein L B. Analysis of the defects responsible for the impaired regulation of EBVinduced B-cell proliferation by RA lymphocytes. I. Diminished gamma interferon production in response to autologous stimulation. J Exp Med 1983; 157: 173-88. 